\title{
BMJ Open Characteristics of self-management among patients with complex health needs: a thematic analysis review
}

\author{
Annie-Pier Gobeil-Lavoie, ${ }^{1}$ Maud-Christine Chouinard, ${ }^{1}$ Alya Danish, ${ }^{2}$ \\ Catherine Hudon ${ }^{2}$
}

To cite: Gobeil-Lavoie A-P, Chouinard M-C, Danish A, et al. Characteristics of self-management among patients with complex health needs: a thematic analysis review. BMJ Open 2019;9:e028344. doi:10.1136/ bmjopen-2018-028344

- Prepublication history for this paper is available online. To view these files please visit the journal online (http://dx.doi. org/10.1136/bmjopen-2018028344).

Received 3 December 2018 Revised 23 April 2019 Accepted 7 May 2019

Check for updates

(c) Author(s) (or their employer(s)) 2019. Re-use permitted under CC BY-NC. No commercial re-use. See rights and permissions. Published by BMJ.

${ }^{1}$ Département des sciences de la santé, Université du Québec à Chicoutimi, Chicoutimi, Québec, Canada

${ }^{2}$ Department of Family Medicine and Emergency Medicine, Université de Sherbrooke, Sherbrooke, Quebec, Canada

Correspondence to Professor Catherine Hudon; catherine.hudon@usherbrooke. ca

\section{ABSTRACT}

Objective There is a gap of knowledge among healthcare providers on characteristics of self-management among patients with chronic diseases and complex healthcare needs. Consequently, the objective of this paper was to identify characteristics of self-management among patients with chronic diseases and complex healthcare needs.

Design Thematic analysis review of the literature. Methods We developed search strategies for the MEDLINE and CINAHL databases, covering the January 2000-0ctober 2018 period. All articles in English or French addressing self-management among an adult clientele (18 years and older) with complex healthcare needs (multimorbidity, vulnerability, complexity and frequent use of health services) were included. Studies that addressed self-management of a single disease or that did not have any notion of complexity or vulnerability were excluded. A mixed thematic analysis, deductive and inductive, was performed by three evaluators as described by Mileset al. Results Twenty-one articles were included. Patients with complex healthcare needs present specific features related to self-management that can be exacerbated by deprived socioeconomic conditions. These patients must often prioritise care based on one dominant condition. They are at risk for depression, psychological distress and low self-efficacy, as well as for receiving contradictory information from healthcare providers. However, the knowledge and experiences acquired in the past in relation to their condition may help them improve their selfmanagement skills.

Conclusions This review identifies challenges to selfmanagement for patients with complex healthcare needs, which are exacerbated in contexts of socioeconomic insecurity and proposes strategies to help healthcare providers better adapt their self-management support interventions to meet the specific needs of this vulnerable clientele.

\section{INTRODUCTION}

A great majority of patients who consult the healthcare system worldwide present with one or more chronic diseases. ${ }^{1}$ Responsible for $63 \%$ of deaths, chronic diseases represent the first cause of mortality in the world. ${ }^{2}$ Characterised by periods of stability and deteriorations, the health condition of people
Strengths and limitations of this study

The analysis was conducted using a recognised conceptual model of self-management.

- There is a lack of consensus in the literature regarding the definition of patients with complex needs, so we ensured that the selection criteria developed for this study were broad enough to include a range of definitions for complexity.

- A limitation of any review is the potential omission of relevant articles as well as any unpublished material.

with chronic diseases requires constant attention by the persons who are affected, as well as by those who surround them, in order to manage symptoms and consequences. People with chronic diseases often have to develop self-management skills.

Self-management has been defined as 'the practice of activities that individuals initiate and perform on their own behalf in maintaining life, health, and well-being' and 'developing the skills needed to devise, implement, evaluate, and revise an individualised plan for lifestyle change'. ${ }^{3}$ Self-management incorporates an array of skills that a person must possess in order to take charge of his or her health. Lorig and Holman ${ }^{4}$ developed a theoretical model for self-management involving three self-management tasks: medical management, emotional management and role management. According to this model, self-management requires six self-management skills in the patient: decision making, action planning, development of a patientprovider partnership, self-tailoring, resource utilisation and problem solving.

To date, self-management has mainly been studied in the context of a specific chronic disease, even though the management of a more complex health issue may lead to important self-management challenges. ${ }^{5} 6$ Therefore, there is a gap in knowledge on the ways to offer self-management support to 
patients with complex needs. ${ }^{7}$ Providers constantly work with this clientele whether it be in hospitals, emergency services, medical clinics, in homecare and so on. Thus, they play an important role in self-management support. ${ }^{8}$ However, the scarcity of knowledge on the specifics of self-management among complex patients can be detrimental to healthcare providers' capacity to adequately support and accompany such patients in the self-management of their chronic conditions. Consequently, it is important to increase our understanding of the characteristics of self-management for this clientele, for whom the current norm for care in regards to the management of a single disease may not be appropriate. ${ }^{1}$

The aim of this paper is to review the literature to identify the characteristics of self-management among patients with chronic diseases and complex healthcare needs.

\section{METHODS}

\section{Patient or public participation}

Patients and/or the public were not involved in this study.

\section{Design}

A review of the literature including quantitative, qualitative and mixed studies was conducted on papers addressing the self-management of persons with complex healthcare needs. We followed the same synthesis process of the thematic analysis published in 2012 by Hudon et $a l^{9}$

\section{Search methods}

We conducted an electronic literature search in the MEDLINE and CINAHL databases, for articles in English and in French published between January 2000 and October 2018. An information specialist developed and ran the specific search strategies for each database. The following medical subject heading $(\mathrm{MeSH})$ terms and keywords were used: self-care OR self-management OR self-monitoring AND multimorbidity OR comorbidity OR vulnerability OR complex* OR multiple chronic diseases OR multiple chronic conditions OR frequent users OR high users. We also examined articles found in the reference lists of collected articles (hand search).

\section{Data collection}

All search results were transferred to the Endnote X7 reference software and duplicates were eliminated. Articles retained had to respect the following criteria: (1) refer to self-management, (2) among a clientele with complex healthcare needs (multimorbidity, vulnerability, complexity and frequent use of health services) and (3) in a population of patients 18 years and older. One team member (A-PG-L) read all titles and abstracts to exclude articles that were clearly not eligible. We excluded references that did not meet our inclusion criteria and retained all other references for complete evaluation. Two reviewers (A-PG-L and CH or A-PG-L and M-CC) independently appraised the full text of the retained

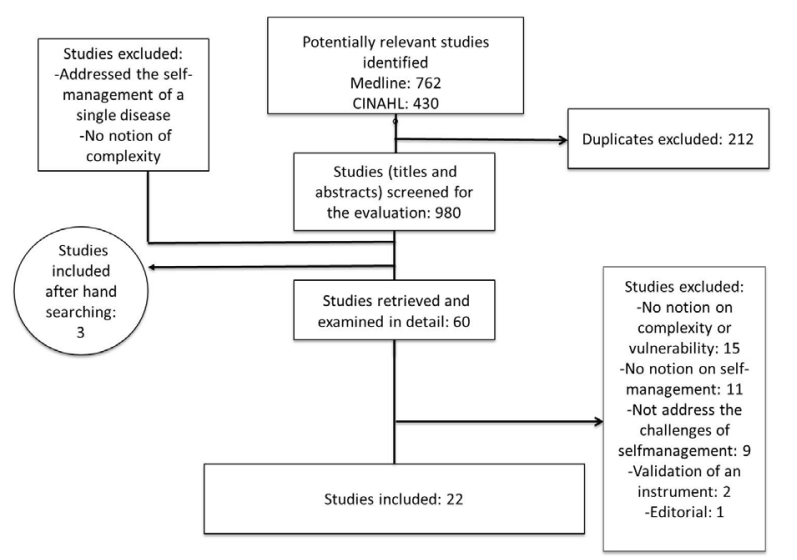

Figure 1 Number of references found.

papers to identify potentially eligible articles. Discrepancies between the two reviewers regarding the inclusion or exclusion of papers were resolved by the third evaluator.

\section{Analysis and synthesis}

All selected articles were imported into the NVivo 11 qualitative analysis software. A mixed thematic analysis, deductive and inductive, was then performed on the results of the articles by three evaluators as described by Miles et al, ${ }^{10}$ using the Lorig and Holman model (six self-management skills and three self-management tasks). ${ }^{4}$ Excerpts were extracted from each of the reviewed articles and classified according to the self-management skills and tasks particular to patients with complex care needs. A second reading of the collected excerpts and familiarisation with the data allowed for the identification of emergent themes. Pair debriefing and team validation minimised the influence of researcher subjectivity and preconceptions. ${ }^{11}$ This was an iterative process where interpretations of the data extracted from the articles were validated, and where disagreements or questions were discussed and resolved by consensus among the three evaluators.

\section{RESULTS}

Included studies

Figure 1 shows the number of references found at each stage of the selection process. The search strategies identified 1192 references, of which 980 were kept after removing duplicates. The majority of these references were rejected because they addressed the self-management of a single disease and did not contain any notion of complexity. References found through hand searching $(n=3)$ were also included, for a total of 60 potentially eligible references. Sixty papers were read completely. Of these, 38 articles were excluded after the full reading step: 15 did not contain any notion of complexity in the studied population; 11 did not address self-management; 9 did not address the challenges of self-management; 1 was an editorial; and 2 articles were on the validation of a measuring tool. A final sample of 22 articles was retained. Table 1 presents the characteristics of the included studies. 
Table 1 Characteristics of the articles included $(n=22)$

Number of articles

\begin{tabular}{|c|c|}
\hline \multicolumn{2}{|l|}{ Type of publication/study design } \\
\hline Qualitative studies 67121618 31-33 & 8 \\
\hline Quantitative studies $^{141719212334}$ & 6 \\
\hline Mixed methods ${ }^{515}$ & 2 \\
\hline Recommendations of a working group ${ }^{1}$ & 1 \\
\hline Reviews $^{132235-37}$ & 5 \\
\hline \multicolumn{2}{|l|}{ Principal authors location } \\
\hline USA $^{15-71213151723323335}$ & 12 \\
\hline$U^{14161819}$ & 4 \\
\hline Canada 223137 & 3 \\
\hline Australia $^{2134}$ & 2 \\
\hline Finland $^{36}$ & 1 \\
\hline \multicolumn{2}{|l|}{ Complexity referred to in the article } \\
\hline Multimorbidity & 10 \\
\hline Vulnerability 51521313335 & 6 \\
\hline Complexity 16712173237 & 7 \\
\hline Frequent users ${ }^{14172123}$ & 4 \\
\hline
\end{tabular}

\section{Characteristics of self-management by patients with complex} health needs

Five main themes emerged that describe the distinctive features of self-management in these patients.

Need for prioritisation of self-care

Prioritisation of self-care is an important self-management challenge for patients with multiple chronic diseases. When the number of self-care activities or tasks to accomplish surpasses the amount of time available, patients will establish a daily plan around the management of their chronic conditions ${ }^{12}$ and must inevitably determine which self-care activities to prioritise. Patients with multimorbidity prioritise self-care activities based on the identification of one dominant condition. ${ }^{13}$

Three types of conditions are more frequently identified as dominant: a poorly controlled condition that tends to cause important exacerbations or negatively affect the control of other conditions, a condition that cannot be controlled solely by medication or an unstable condition for which it is impossible to anticipate daily self-management needs. The patient is more likely to adopt a self-management strategy if he or she thinks that it will benefit more than one condition. ${ }^{6} 1415$

\section{Lack of motivation and greater risk for depression}

Patients with complex needs may experience less energy and lack time and motivation to take part in self-management activities. ${ }^{16} 17$ They report feelings of sadness, anger and anxiety related to their illness. ${ }^{12}$ They are at an increased risk for depression. ${ }^{17}$ The emotional impact of disease can play an important role in decision making. A depressive state may give patients the impression that they are not capable of participating in self-management activities. ${ }^{13} 18$ Even when patients are committed to adopting healthier lifestyle habits, they admit that depression could delay them from taking action. ${ }^{161719}$ If they focus on their inability to control a situation, patients tend to ruminate on the negative aspects of their health status and sink into emotional distress that prevents them from taking appropriate action when faced with a problem. ${ }^{15}$

\section{Increased risk of presenting poor self-efficacy}

Self-efficacy is an important mediator of taking action. People's beliefs about their own self-efficacy reflect 'their capabilities to produce designated levels of performance that exercise influence over events that affect their lives' and determine how they 'feel, think and motivate themselves and behave' (p. 72)..$^{20}$ Patients with numerous comorbidities are more at risk of poor self-efficacy. ${ }^{19} \mathrm{~A}$ person with low self-efficacy may experience difficulty in taking action to change lifestyle habits or in preventing the exacerbation of symptoms, leading to frequent hospital visits. ${ }^{21}$

Patients with multimorbidity living in underprivileged neighbourhoods have lower expectations in regard to health and ageing than patients from privileged neighborhoods. ${ }^{16}$ Patients living in situations of poverty often perceive that their poor health status is the norm, which greatly limits their motivation to improve their health. ${ }^{16}$ They may believe that if others are not able to improve their health status, neither will they. Social isolation can also affect the self-efficacy of these patients who think they do not have the capacity to engage in self-management activities. ${ }^{16}$ Support of family, friends and health providers can play an important role to improve self-efficacy. ${ }^{21}$

\section{Increased risk of receiving conflicting information}

Patients with complex care needs are at risk of receiving conflicting information on the management of their diseases by the numerous health professionals that they meet. ${ }^{6} 1822$ This can lead to increased anxiety and decreased self-management capacity. ${ }^{14}$

A personalised evaluation of learning capacity, behaviour change and the desire to commit to self-management, as well as regular monitoring, facilitates patient self-management. Initiating too many changes at one time may overload the patient and his or her self-management capacity. ${ }^{122}$ Treatment goals should be selected based on patient motivation and willingness to change. ${ }^{23}$

\section{Opportunity to use personal experience}

Complex healthcare needs do not necessarily require a new set of practices for each new diagnosis. Patients with complex care needs can use the knowledge and personal experience acquired in the past and apply them in various situations to better manage their health. ${ }^{18} 22$ However, economic hardship reduces structural and emotional capacity, which may often prevent people living in economically precarious areas from adopting self-management 
behaviours that have synergistic effects on many of their health issues. ${ }^{16}$

\section{DISCUSSION}

Patients with complex healthcare needs are confronted with self-management challenges, these being exacerbated in the presence of socioeconomic insecurity. These patients must often prioritise self-care according to one dominant condition. They are at risk for depression, psychological distress and low self-efficacy, as well as for receiving contradictory information from healthcare providers. However, their previous experiences may help them improve their self-management skills.

Liddy $e t a t^{22}$ conducted a literature review aiming to explore barriers to self-management through the perspective of patients living with multiple chronic conditions. Of the 21 articles used in our thematic analysis, seven of them were also included in their review. Common themes emerged from both studies, such as contradictory information and high risk for depression. Our analysis also highlights other particularities such as poor self-efficacy, often observed in this clientele, and the fact that patients frequently rely on past experience to adequately take charge of their health.

One of the main challenges of self-management is the prioritisation of self-care. Patients with numerous chronic diseases are constantly confronted with having to make choices among the care activities to prioritise. Most will identify a dominant disorder on which to focus their efforts. ${ }^{13}$ In certain situations, the characteristics of a condition are in conflict with the management of others and the successful management of a condition can hinder the taking in hand of another. ${ }^{24}$ Patients will more easily accept to engage in self-care activities that they consider beneficial to more than one of their conditions. ${ }^{61415}$ Social and economic conditions will influence how patients prioritise self-care. ${ }^{25}$ The healthcare provider can explore the reasons that guide this prioritisation for a given patient. Interventions may have a greater impact if the healthcare provider takes time to explain the benefits of self-management behaviours for the different conditions facing the patient.

Depression and emotional distress may impair self-management by decreasing motivation, prioritisation skills and problem solving. Negative emotions may also decrease self-confidence and self-efficacy, ${ }^{26}$ and distress is often present in this vulnerable clientele. ${ }^{27}{ }^{28}$ Healthcare providers must remain vigilant during their self-management support activities with this clientele, for the quick detection of psychological distress and the treatment of mental health issues.

Patients with complex care needs reported receiving conflicting information from the health professionals they consulted. Between 25\% and $80 \%$ of patients received contradictory information on their diseases and their management. ${ }^{29}$ Receiving conflicting information from two sources that the person trusts can complicate self-management. ${ }^{29}$ In order to help these patients as much as possible, it is important that healthcare providers offer a personalised evaluation of their needs, as well as proper follow-up, and ensure good coordination between various health professionals. ${ }^{23}$

Although the majority of studies report that complexity is an additional challenge to self-management, the coexistence of many chronic conditions can also become an opportunity to call on past learning experiences. ${ }^{30}$ The healthcare provider can help the patient become aware of the knowledge and skills gained in the past as well as positive experiences.

\section{Limitations}

Our study presents some limitations. There is a lack of consensus in the literature regarding the definition of patients with complex needs. We ensured that the selection criteria developed for this study were broad enough to include a range of definitions for complexity. A limitation of any review is the potential omission of relevant articles as well as any unpublished material. However, all necessary measures were taken to ensure an exhaustive document review: our search strategy was adapted to various databases and was developed in collaboration with an information specialist. Furthermore, we identified additional papers by hand search.

\section{CONCLUSIONS}

Patients with complex health needs present challenges to self-management related to the prioritisation of self-care, a greater risk for depression or psychological distress, a greater risk of poor self-efficacy and the risk of receiving conflicting information from healthcare professionals. However, they can rely on their knowledge and previous experience gained in other situations to improve their self-management skills. Future studies could empirically validate the results of this research and contribute to the understanding of the experience of these patients. Healthcare providers can learn from these results to better adapt their self-management support interventions to meet the specific needs of this vulnerable clientele.

Acknowledgements The authors would like to thank Ms Janie Gauthier, an information specialist at Université du Québec à Chicoutimi for her help in the development and running of specific search strategies for each database and Ms Susie Bernier for her contribution to the translation of the article to English.

Contributors APGL found the articles, analysed, interpreted the data and drafted the manuscript with the participation of $A D$, under the supervision of $M C C$ and $C H$. MCC and $\mathrm{CH}$ coanalysed and interpreted the data. All authors approved and read the manuscript.

Funding The authors have not declared a specific grant for this research from any funding agency in the public, commercial or not-for-profit sectors.

Competing interests None declared.

Patient consent for publication Not required.

Provenance and peer review Not commissioned; externally peer reviewed. Data sharing statement No additional data are available.

Open access This is an open access article distributed in accordance with the Creative Commons Attribution Non Commercial (CC BY-NC 4.0) license, which 
permits others to distribute, remix, adapt, build upon this work non-commercially, and license their derivative works on different terms, provided the original work is properly cited, appropriate credit is given, any changes made indicated, and the use is non-commercial. See: http://creativecommons.org/licenses/by-nc/4.0/.

\section{REFERENCES}

1. Bayliss EA, Bosworth HB, Noel PH, et al. Supporting selfmanagement for patients with complex medical needs: recommendations of a working group. Chronic IIIn 2007;3:167-75.

2. World Health Organization. Maladies chroniques. 2017 http://www. who.int/topics/chronic_diseases/fr/ (accessed 03-05 2015).

3. Orem DE. Nursing: concepts of practice. St Louis, MO: Mosby-Year Book Inc, 1991.

4. Lorig KR, Holman H. Self-management education: history, definition, outcomes, and mechanisms. Ann Behav Med 2003;26:1-7.

5. Bardach SH, Tarasenko YN, Schoenberg NE. The role of social support in multiple morbidity: self-management among rural residents. J Health Care Poor Underserved 2011;22:756-71.

6. Bayliss EA, Ellis JL, Steiner JF. Barriers to self-management and quality-of-life outcomes in seniors with multimorbidities. Ann Fam Med 2007:5:395-402.

7. Sevick MA, Trauth JM, Ling BS, et al. Patients with complex chronic diseases: perspectives on supporting self-management. J Gen Intern Med 2007;22(Suppl 3):438-44.

8. Registered Nurses' Association of Ontario. Stratégies permettant de soutenir l'autogestion des états chroniques : la collaboration avec les clients. Toronto, ON, 2010.

9. Hudon C, Fortin M, Haggerty J, et al. Patient-centered care in chronic disease management: a thematic analysis of the literature in family medicine. Patient Educ Couns 2012;88:170-6.

10. Miles MB, Huberman MA, Santana J. Qualitative data analysis: a method sourcebook. London: Sage, 2014.

11. Creswell JW. Quantitative inquiry \& research design: choosing among five approaches. Thousand Oaks, CA: Sage, 2006.

12. Restorick Roberts A, Betts Adams K, Beckette Warner C. Effects of chronic illness on daily life and barriers to self-care for older women: A mixed-methods exploration. J Women Aging 2017;29:126-36.

13. Bratzke LC, Muehrer RJ, Kehl KA, et al. Self-management priority setting and decision-making in adults with multimorbidity: a narrative review of literature. Int J Nurs Stud 2015;52:744-55.

14. Bower P, Hann M, Rick J, et al. Multimorbidity and delivery of care for long-term conditions in the English National Health Service: baseline data from a cohort study. J Health Serv Res Policy 2013;18(2 Suppl):29-37.

15. Leach CR, Schoenberg NE. Striving for control: cognitive, selfcare, and faith strategies employed by vulnerable black and white older adults with multiple chronic conditions. J Cross Cult Gerontol 2008;23:377-99.

16. Coventry PA, Fisher L, Kenning C, et al. Capacity, responsibility, and motivation: a critical qualitative evaluation of patient and practitioner views about barriers to self-management in people with multimorbidity. BMC Health Serv Res 2014;14:536.

17. Hill N, Joubert L, Epstein I. Encouraging self-management in chronically ill patients with co-morbid symptoms of depression and anxiety: an emergency department study and response. Soc Work Health Care 2013;52:207-21.

18. Morris RL, Sanders C, Kennedy AP, et al. Shifting priorities in multimorbidity: a longitudinal qualitative study of patient's prioritization of multiple conditions. Chronic IIIn 2011;7:147-61.
19. Harrison M, Reeves D, Harkness E, et al. A secondary analysis of the moderating effects of depression and multimorbidity on the effectiveness of a chronic disease self-management programme. Patient Educ Couns 2012;87:67-73.

20. Self-efficacy BA, V. S I. Ramachaudran: encyclopedia of human behavior. New York: Academic Press, 1994.

21. Gallagher R, Donoghue J, Chenoweth L, et al. Self-management in older patients with chronic illness. Int J Nurs Pract 2008;14:373-82.

22. Liddy C, Blazkho V, Mill K. Challenges of self-management when living with multiple chronic conditions: systematic review of the qualitative literature. Can Fam Physician 2014;60:1123-33.

23. Noël PH, Parchman ML, Williams JW, et al. The challenges of multimorbidity from the patient perspective. J Gen Intern Med 2007;22(Suppl 3):419-24.

24. Mc Sharry J, Bishop FL, Moss-Morris R, et al. 'The chicken and egg thing': cognitive representations and self-management of multimorbidity in people with diabetes and depression. Psychol Health 2013;28:103-19.

25. Bosworth HB, Powers BJ, Oddone EZ. Patient self-management support: novel strategies in hypertension and heart disease. Cardiol Clin 2010;28:655-63.

26. Lin MT, Burgess JF, Carey K. The association between serious psychological distress and emergency department utilization among young adults in the USA. Soc Psychiatry Psychiatr Epidemiol 2012;47:939-47.

27. Dinkel A, Schneider A, Schmutzer G, et al. Family physician-patient relationship and frequent attendance of primary and specialist health care: Results from a German population-based cohort study. Patient Educ Couns 2016;99:1213-9.

28. Fortin M, Bravo G, Hudon C, et al. Psychological distress and multimorbidity in primary care. Ann Fam Med 2006;4:417-22.

29. Elstad E, Carpenter DM, Devellis RF, et al. Patient decision making in the face of conflicting medication information. Int J Qual Stud Health Well-being 2012;7:18523-12.

30. Vellone E, Riegel B, D'Agostino F, et al. Structural equation model testing the situation-specific theory of heart failure self-care. Journal of Advanced Nursing 2013;69:30-4.

31. Clarke LH, Bennett EV. Constructing the moral body: self-care among older adults with multiple chronic conditions. Health 2013;17:211-28.

32. Eton DT, Ridgeway JL, Egginton JS, et al. Finalizing a measurement framework for the burden of treatment in complex patients with chronic conditions. Patient Relat Outcome Meas 2015;6:117-26.

33. Roberto KA, Gigliotti CM, Husser EK. Older women's experiences with multiple health conditions: daily challenges and care practices. Health Care Women Int 2005;26:672-92.

34. Islam MM, McRae IS, Yen L, et al. Time spent on health-related activities by senior Australians with chronic diseases: what is the role of multimorbidity and comorbidity? Aust N Z J Public Health 2015;39:277-83.

35. Dorsey CJ, Murdaugh CL. The theory of self-care management for vulnerable populations. Journal of Theory Construction \& Testing 2003;7:43-9.

36. Hujala A, Rijken M, Laulainen S, et al. People with multimorbidity: forgotten outsiders or dynamic self-managers? J Health Organ Manag 2014;28:696-712.

37. Novak M, Costantini L, Schneider S, et al. Approaches to selfmanagement in chronic illness. Semin Dial 2013;26:188-94. 